\title{
Mutations in the Membrane-Anchored SdhC Subunit Affect Fitness and Sensitivity to Succinate Dehydrogenase Inhibitors in Botrytis cinerea Populations from Multiple Hosts
}

\author{
Achour Amiri, ${ }^{1, \dagger}$ Adrian I. Zuniga, ${ }^{2}$ and Natalia A. Peres ${ }^{2}$ \\ ${ }^{1}$ Washington State University, Tree Fruit Research and Education Center, Wenatchee, WA 98801 \\ ${ }^{2}$ University of Florida, Gulf Coast Research and Education Center, Wimauma, FL 33598 \\ Accepted for publication 4 September 2019.
}

\begin{abstract}
Succinate dehydrogenase inhibitors (SDHIs) are an essential group of fungicides for managing gray mold, caused by Botrytis cinerea, in numerous crops. Resistance to boscalid, an early-generation SDHI, is widespread worldwide and was linked to mutations in the iron-sulfur protein encoding the SdhB subunit of the SDH complex. Herein, we report on four simultaneous dependent mutations at codons 85 (G85A), 93 (I93V), 158 (M158V), and 168 (V168I) of the membrane-anchored SdhC subunit of B. cinerea. Isolates without and with mutations in SdhC were referred to as $\mathrm{C}^{-}$and $\mathrm{C}^{+}$genotypes, respectively. The $\mathrm{C}^{+}$genotype was found in all the five surveyed hosts from different U.S. regions but its frequency was higher, 25 to $40 \%$, in the tree fruit isolates compared with 12 to $25 \%$ in the small fruit populations. The four SdhC mutations were found in isolates without mutations in SdhB or with mutations known to confer resistance to the SDHIs in SdhB. However, the frequency of $\mathrm{C}^{+}$ isolates was significantly higher in the $\mathrm{SdhB}$ wild-type isolates, which suggests that SDHI sprays may have played a role in selecting for the
\end{abstract}

ABSTRACT

Botrytis cinerea Pers. (teleomorph Botryotinia fuckeliana) is a ubiquitous fungal plant pathogen causing gray mold on various fruit, vegetable, and ornamental crops (Elad et al. 2004; Williamson et al. 2007). The pathogen is difficult to control because of its extensive host range, genetic diversity, and mode of reproduction (Elad et al. 2004; Williamson et al. 2007). Recent findings indicated that Botrytis cinerea may suppress plant immunity by hijacking host defense systems (Weiberg et al. 2013), which may limit the use of any potential resistant cultivars. Currently, chemical control remains the most effective method for gray mold management. Fungicides from multiple chemical classes and different modes of action have been developed to control gray mold on various crops. However, continuous selective pressure resulted in populations of $B$. cinerea increasingly resistant to multiple fungicides simultaneously (Amiri et al. 2013; Bardas et al. 2010; Fernández-Ortuño et al. 2014; Leroch et al. 2012; Leroux et al. 1999; Myresiotis et al. 2007). For example, resistance to fungicides from six chemical classes has been reported in $B$. cinerea populations from strawberry fields across the eastern United States (Amiri et al. 2013; FernándezOrtuño et al. 2014). In pome fruit, lower resistance frequencies of approximately $20 \%$ have been reported from the U.S. Pacific

†Corresponding author: A. Amiri; a.amiri@wsu.edu

Funding: This research was funded by a United States Department of AgricultureNational Institute of Food and Agriculture fund under project number 2010-5118121113 and a grant from the Washington Tree Fruit Research Commission under project number AP-16-105.

The author(s) declare no conflict of interest.

(c) 2020 The American Phytopathological Society
$\mathrm{C}^{-}$over the $\mathrm{C}^{+}$genotype. Field $\mathrm{C}^{+}$isolates exhibited reduced sensitivity to fluopyram and increased sensitivity to boscalid and penthiopyrad in vitro and on detached fruit. Homology modeling confirmed the positioning of the four mutations in the ubiquinone-binding pocket. The SdhCG85A is found in the proximal ubiquinone binding site and $\mathrm{SdhC}^{\mathrm{M} 158 \mathrm{~V}}$ is positioned in the iron sulfur protein interface next to the [3Fe-4S] cluster, whereas $\mathrm{SdhC}^{\mathrm{I} 93 \mathrm{~V}}$ is positioned next to the heme $b$ with vital functions in the SDH enzyme. Beside the differential sensitivity to the SDHIs, these mutations caused a significant fitness cost in the $\mathrm{C}^{+}$isolates including sporulation and increased sensitivity to reactive oxygen species. The presence of Botrytis populations differentially sensitive to the SDHIs suggests increased risks for resistance development but also opens up new perspective for future gray mold management using different SDHI fungicides.

Keywords: disease control and pest management, mycology
Northwest (Kim and Xiao 2010; Yin et al. 2011), most likely due to lower fungicide input compared with small fruit.

The carboxamides, or succinate dehydrogenase inhibitors (SDHIs), constitute one of the largest chemical groups used in agriculture and the most fast-growing class of fungicides, with at least seven new products registered since 2012 (FRAC 2018). The SDHIs target complex II, also known as succinate dehydrogenase (SDH), one of the four complexes of the respiratory chain of enzymes of the mitochondrial inner membrane. SDH is an oxidoreductase enzyme that catalyzes the oxidation of succinate to fumarate with the reduction of quinone to quinol (Cecchini 2003; Hägerhäll 1997; Horsefield et al. 2004; Lancaster 2002). The enzyme consists of two hydrophilic larger polypeptides, the flavoprotein (SdhA, approximately 60 to $70 \mathrm{kDa}$ ) and the iron-sulfur protein (SdhB, approximately $27 \mathrm{kDa}$ ) which contains three iron sulfur clusters (i.e., [2Fe-2S] next to SdhA, [4Fe-4S] in the center of $\mathrm{SdhB}$, and [3Fe-4S] located next to the membrane interface) (Cecchini 2003; Lancaster 2002). These two subunits are anchored to the mitochondrial membrane by two smaller hydrophobic polypeptides-SdhC (approximately $15 \mathrm{kDa}$ ), encoding the cytochrome $b_{560}$, and $\mathrm{SdhD}$ (approximately $9 \mathrm{kDa}$ ) — in addition to a heme b $\left(H_{b}\right)$ interfaced between the SdhC and SdhD subunits (Cecchini 2003; Lancaster 2002). Amino acid sequences of the SdhA and SdhB subunits are highly conserved among species in contrast to the SdhC and SdhD subunits. The ubiquinone-binding pocket $\left(Q_{P}\right)$, involving conserved amino acids from SdhB (W164 and H207), SdhC (S27), and SdhD (W83) in Escherichia coli (Cecchini 2003; Horsefield et al. 2006), equivalent to SdhB (W229 and H272), SdhC (S84), and $\mathrm{SdhD}$ (W144) in B. cinerea, is of a particular importance. By binding to the residues forming the $Q_{P}$, the SDHIs interact with ubiquinone reduction which, ultimately, alters the fungal respiration pathway. 
Resistance to carboxin, flutolanil, and boscalid, the first SDHIs used in agriculture, was linked to multiple mutations in three of the four SDH subunits (i.e., SdhB, SdhC, and SdhD). Among the 14 pathogens in which resistance to the aforementioned SDHIs has been reported thus far, 11, 9, and 6 mutations were found in the SdhC, SdhB, and SdhD subunits, respectively (Amiri et al. 2014; Avenot et al. 2008, 2009; Fraaije et al. 2012; Leroux et al. 2010; Scalliet et al. 2012; Shima et al. 2009; Sierotzki and Scalliet 2013; Stammler et al. 2008). In B. cinerea field isolates resistant to boscalid, seven mutations at five codons of $\mathrm{SdhB}$ and at one codon in $\mathrm{SdhD}$ have been reported (Amiri et al. 2014; Leroux et al. 2010; Veloukas et al. 2011). The two most frequent mutations in B. cinerea occur at codon 272 $\left(\mathrm{SdhB}^{\mathrm{H} 272 \mathrm{R} / \mathrm{Y}}\right)$ located near the highly conserved [3Fe-4S] iron-sulfur cluster of the SdhB subunit (Amiri et al. 2014; De Miccolis Angelini et al. 2010; Leroux et al. 2010; Veloukas et al. 2011; Yin et al. 2011). Less frequent mutations have also been reported at codons 272 $\left(\mathrm{SdhB}^{\mathrm{H} 272 \mathrm{~L}}\right), 225$ (SdhB $\left.{ }^{\mathrm{P} 225 \mathrm{~F}}\right)$, and 230 (SdhB $\left.{ }^{\mathrm{N} 230 \mathrm{I}}\right)$. The highest numbers of mutations conferring resistance to the SDHIs have been reported in SdhC of several fungal species such as Alternaria alternata and A. solani (Fairchild et al. 2012; Fraaije et al. 2012), Aspergillus oryzae (Shima et al. 2009), Coprinus cinereus (Ito et al. 2004), and Mycosphaerella graminicola (Fraaije et al. 2012; Scalliet et al. 2012) but none was reported thus far in the SdhC of B. cinerea.

Numerous studies documented various sensitivity and resistance phenotypes in $B$. cinerea isolates with or without mutations in the SdhB subunit (Amiri et al. 2014; Fernández-Ortuño et al. 2012; Leroux et al. 2010; Miyamoto et al. 2010; Veloukas et al. 2011; Weber and Hahn 2011). For example, several wild-type isolates from strawberry fields in Florida (Amiri et al. 2014), the Carolinas (Fernández-Ortuño et al. 2012), and Germany (Weber and Hahn 2011) were characterized as highly sensitive (HS) to boscalid compared with other sensitive (S) isolates. The HS isolates were not able to germinate on a sublethal dose used for characterization, in contrast to the $\mathrm{S}$ isolates. In Botrytis populations from Florida strawberry fields, $15 \%$ of isolates did not have a mutation in $\mathrm{SdhB}$ but were moderately resistant to boscalid (Amiri et al. 2014). Moreover, $10 \%$ of the $\mathrm{SdhB}^{\mathrm{H} 272 \mathrm{Y}}$ B. cinerea mutants, known to be HS to fluopyram, showed reduced sensitivity to fluopyram (Amiri et al. 2014), whereas C. cassiicola isolates moderately resistant to boscalid were highly resistant to fluopyram (Ishii et al. 2011; Miyamoto et al. 2010). In addition to the possible variable intrinsic sensitivities between isolates and differential affinity of SDHIs to the target sites, additional resistance mechanisms could cause such discrepancies in sensitivity levels.

Following a study on resistance to numerous SDHIs in $B$. cinerea from Florida strawberry fields (Amiri et al. 2014), sequencing of the SdhC subunit revealed that some isolates with or without mutations in SdhB also carried four concurrent mutations in SdhC. Herein, concurrent mutations refer to the simultaneous presence of the three other mutations if the first one is observed. The isolates without or with mutations in the $\mathrm{SdhC}$ are referred to as $\mathrm{C}^{-}$and $\mathrm{C}^{+}$, respectively. In the this study, we (i) determined the different mutations occurring in the $\mathrm{SdhB}$ subunit from a large Botrytis population; (ii) investigated the distribution of $\mathrm{C}^{-}$and $\mathrm{C}^{+}$genotypes in five different hosts and geographic U.S. regions; (iii) evaluated the sensitivity of $\mathrm{C}^{-}$and $\mathrm{C}^{+}$field isolates to three SDHIs (boscalid, penthiopyrad, and fluopyram) and to fludioxonil, cyprodinil, and fenhexamid; and (iv) evaluated the effect of the SdhC mutations on several fitness parameters in $B$. cinerea isolates.

\section{MATERIALS AND METHODS}

Botrytis isolates. In all, 558 Botrytis spp. isolates collected from 40 different locations (fields and orchards) in Florida, South Carolina, North Carolina, Washington, and Oregon were used to investigate the presence of mutations in the $\mathrm{SdhC}$ subunit. Isolates were collected from five different hosts that included apple, cherry, blueberry, pear, and strawberry (Table 1). The SDHI boscalid, premixed with pyraclostrobin (Pristine; BASF, Research Triangle Park, NC, U.S.A.), has been used regularly since 2004 in all fields and orchards surveyed. Florida strawberry fields surveyed in 2013 and 2014 have been sprayed with penthiopyrad and fluopyram since 2012. Thirty baseline isolates from strawberry fields in the Carolinas, characterized previously as HS or $\mathrm{S}$ to boscalid (Fernández-Ortuño et al. 2012), were used in this study. Blueberry isolates were obtained from flowers and fruit collected in 2013 and 2014 from five commercial fields in Central Florida. Isolates from apple, cherry, and pear were obtained from rotten fruit collected from packinghouses in Washington State (apple and cherry) and Oregon (pear only) between 2000 and 2011. In all, 40 and 120 isolates from strawberry were used for sequencing and to assess sensitivity to four SDHIs, respectively, as described below. Thirtytwo strawberry isolates from different genotypes were used to evaluate the fitness parameters and seven apple isolates were used to assess efficacy of three SDHIs on detached apples. All 588 isolates were screened for the presence of $B$. cinerea, B. pseudocinerea, Botrytis group S, and MDRh1 phenotype, as described previously (Amiri et al. 2018; Fournier et al. 2003; Leroch et al. 2012).

Characterization of mutations in the SDH subunits from Botrytis field isolates and SDH homology modeling. DNA was extracted from 7- to 10-day-old conidia and mutations in the $\mathrm{SdhB}$ were characterized as described previously (Amiri et al. 2014). Fragments including the SdhC and SdhD subunits were amplified from 10 sensitive isolates and 30 isolates from strawberry, with different levels of resistance to boscalid, using the primer sets shown in Table 2. PCR assays were performed in a PTC-200 thermal cycler (MJ Research, Waltham, MA, U.S.A.) using an initial denaturation at $95^{\circ} \mathrm{C}$ for $3 \mathrm{~min}$; followed by 35 cycles of $94^{\circ} \mathrm{C}$ for $40 \mathrm{~s}, 55^{\circ} \mathrm{C}$ for $40 \mathrm{~s}$, and $72^{\circ} \mathrm{C}$ for $1 \mathrm{~min}$; and a final extension at $72^{\circ} \mathrm{C}$ for $5 \mathrm{~min}$. Resulting PCR products were purified and used for sequencing. Four mutations were found at codons 85, 93, 158, and 168 of $\mathrm{SdhC}$ in some isolates harboring or not harboring mutations in the $\mathrm{SdhB}$ subunit. A unique BsmaI restriction site (GTCTCN/) was detected at codon 85 of $\mathrm{SdhC}$ of isolates not carrying the four mutations $\left(\mathrm{C}^{-}\right)$. Therefore, a PCR restriction fragment length polymorphism (RFLP) assay was developed to detect the substitution at the SdhCG85 amino acid. The primer pair SdhC-F2/SdhC-R2 (Table 2) was used to amplify a 850-bp fragment of SdhC using the same parameters described above. Resulting PCR products were digested with the BsmaI enzyme (New England BioLabs) and separated on a $2 \%$ agarose gel. The PCR-RFLP was used to characterize the $\mathrm{C}^{-}$from $\mathrm{C}^{+}$genotype in $558 \mathrm{~B}$. cinerea isolates from five hosts.

The three-dimensional structure of the partial SDH protein of B. cinerea was modeled based on a structure template of the SDH protein from the Sus scrofa (porcine) SDH complex II (Protein Database Bank PDB, accession number 3AE2) with OH-phenylbenzamide at the Q-binding site using the PyMOL 0.99rc6 program (DeLano Scientific LLC, San Francisco, CA, U.S.A.) to represent the mutations observed in the $\mathrm{SdhC}$ subunit of Botrytis isolates.

Fungicide sensitivity assays in isolates from the $\mathbf{C}^{-}$and $\mathrm{C}^{+}$ genotypes. The sensitivity of 120 isolates, i.e., $70 \mathrm{C}^{-}$isolates (no mutations in $\mathrm{SdhC}$ ) and $50 \mathrm{C}^{+}$isolates (with mutations in $\mathrm{SdhC}$ ) was evaluated to fluopyram (Luna Privilege; Bayer Crop Science, Research Triangle Park, NC, U.S.A.), penthiopyrad (Fontelis; Dupont Crop Protection, Wilmington, DE, U.S.A.), boscalid (Endura; BASF), and carboxin (Santa Cruz Biotech., Santa Cruz, CA, U.S.A.) using a conidial germination and germ-tube elongation assay on yeast-peptone-acetate agar (YBA) medium (Miyamoto et al. 2010; Stammler et al. 2008). Autoclaved YBA was amended with boscalid, fluopyram, carboxin, or penthiopyrad at 0.0, 0.1, 0.5, 1.0, $5.0,10$ and $50 \mu \mathrm{g} / \mathrm{ml}$ and poured into $15-\mathrm{cm}$ Petri dishes. The plates were divided into 60 squares (external bottom side of the plate), allowing testing for 60 isolates simultaneously on each plate. Two $7-\mu l$ droplets from a conidial suspension at $10^{5}$ conidia/ml were placed inside each square for each isolate. Two replicate plates were used for each 60-isolate subsample and the test was repeated twice. 
Germination (\%) and germ tube elongation were evaluated microscopically after $16 \mathrm{~h}$ incubation at $21 \pm 1^{\circ} \mathrm{C}$. Rating was conducted as described previously (Fernández-Ortuño et al. 2014, Weber and Hahn 2011) and values were used to calculate mean effective concentrations of the fungicide to inhibit $50 \%$ germination and growth tube elongation $\left(\mathrm{EC}_{50}\right)$ values. Sensitivity of the $\mathrm{C}^{-}$and $\mathrm{C}^{+}$isolates to cyprodinil (Vangard WG; Syngenta Crop Protection, Greensboro, NC, U.S.A.), fludioxonil (Medallion WP; Syngenta), and fenhexamid (Elevate 50 WDG; Arysta, Cary, NC, U.S.A.) was evaluated as described previously (Fernández-Ortuño et al. 2014).

Efficacy of SDHIs against $\mathrm{C}^{-}$and $\mathrm{C}^{+}$isolates on detached fruit. The efficacy of three SDHIs in controlling gray mold was evaluated for seven $B$. cinerea isolates with or without mutations in the $\mathrm{SdhB}$ and $\mathrm{SdhC}$ subunits; that is, three $\mathrm{C}^{-}(\mathrm{Bc} 769, \mathrm{Bc} 8001$, and $\mathrm{Bc} 4737)$ and four $\mathrm{C}^{+}(\mathrm{Bc} 807, \mathrm{Bc} 1462, \mathrm{Bc} 7425$, and $\mathrm{Bc} 9513)$ isolates isolated from rotten apple fruit. Efficacy tests were conducted on detached organically grown apple (Golden Delicious) prepared and inoculated as described previously (Ali and Amiri 2018). Fruit were wounded and preventively sprayed with the recommended label or equivalent rates of fluopyram (Luna Privilege) or penthiopyrad (Fontelis) at 531 and 1,877 $\mu \mathrm{l} /$ liter, respectively, or with boscalid (Endura) at $0.86 \mathrm{~g} / \mathrm{liter}$. Control fruit were sprayed with sterile water. Eight replicate fruit were used for each isolate-fungicide combination and the experiment was done in triplicate. Fruit were incubated in sterile boxes in a saturated atmosphere at $21 \pm 1^{\circ} \mathrm{C}$ and gray mold incidence and lesion diameter were recorded after 4 and 8 days.

Effect of mutations in the SdhC subunit on fitness of B. cinerea. In all, 32 isolates collected from strawberry, including 16 isolates from each of $\mathrm{C}^{-}$and $\mathrm{C}^{+}$genotypes and 8 isolates from each of the four SdhB genotypes (WT-H272, R272, Y272, and I230) per SdhC genotype (4 isolates for each SdhB-SdhC genotype), were used to study potential fitness penalties caused by the mutations in SdhC. Parameters included growth, sporulation, and sclerotia production on artificial media and on fruit as well as sensitivity to osmotic stress and reactive oxygen species (ROS). To test for mycelial growth, two 5-mm-diameter mycelial plugs, taken from the edge of a growing colony of each isolate, were placed upside down on a potato dextrose agar (PDA) plate. Radial growth was measured after 5 days of incubation at $22^{\circ} \mathrm{C}$ and four plates were used for each isolate. Production of sclerotia was evaluated after 40 days incubation on the same plates used for the mycelial growth assay. Sporulation in vitro was evaluated on malt yeast agar (MYA) plates inoculated with mycelial plugs as described above, using four plates for each isolate.
After 10 days incubation, $15 \mathrm{ml}$ of sterile distilled water were added to each plate, and conidia were carefully scraped from the MYA surface, filtered through cheesecloth, and counted using a hemacytometer. Sporulation on fruit was evaluated on detached blackberry fruit prepared and inoculated as described previously (Amiri et al. 2014). After 10 days incubation at $22^{\circ} \mathrm{C}$, conidia were scraped from the fruit surface using a sterile cotton swab and resuspended in $1 \mathrm{ml}$ of sterile distilled water. Spores were counted as described for sporulation on MYA. The sensitivity to osmotic stress was evaluated on PDA amended with $\mathrm{NaCl}$ at $60 \mathrm{~g} /$ liter as described above for mycelium growth tests and growth was measured after 10 days. Sensitivity to ROS was evaluated on PDA amended with 10, 20, and $40 \mathrm{mM}$ paraquat dichloride (Gramoxone SL, 30.1\% a.i.; Syngenta Crop Protection) to induce ROS formation. Two mycelial plugs were placed upside down on each plate and five plates were used for each isolate. Radial growth was measured after 10 days incubation at $22^{\circ} \mathrm{C}$. All tests were conducted twice.

Data analysis. Data from in vitro sensitivity tests from repeated experiments were combined after homogeneity of variance between experiments was tested using Bartlett's test. A $\chi^{2}$ analysis was conducted to assess the relationship between the mutations in SdhC with the sensitivity level $\left(\mathrm{EC}_{50}\right)$ to the SDHIs. Analysis of variance and mean separations using Fisher's least significant difference were carried out to determine the effect of single SdhC substitutions on the sensitivity to SDHIs and the six fitness parameters. All statistical analyses were performed with JMP statistical software (SAS institute Inc., Cary, NC, U.S.A.).

\section{RESULTS}

The H272R substitution in the $\mathrm{SdhB}$ subunit is predominant in all populations. All 558 isolates tested in this study were characterized as $B$. cinerea because neither $B$. pseudocinerea nor Botrytis group S were detected. Of these 558 isolates, $28.6 \%$ (160 isolates) were characterized as the wild type ( $\left.\mathrm{SdhB}^{\mathrm{WT}}\right)$, with no mutation in the $\mathrm{SdhB}$ subunit, whereas $45.7 \%$ (255 isolates) carried the $\mathrm{SdhB}^{\mathrm{H} 272 \mathrm{R}}$ mutation (Fig. 1A). Overall, 19.3, 7.2, and $2.2 \%$ of isolates carried the $\mathrm{SdhB}^{\mathrm{H} 272 \mathrm{Y}}$, $\mathrm{SdhB}^{\mathrm{N} 230 \mathrm{I}}$, and $\mathrm{SdhB}^{\mathrm{P} 225 \mathrm{~F}}$ mutations, respectively (Fig. 1A).

When grouped by host, isolates from apple, cherry, and pear had a higher frequency of the $\mathrm{SdhB}^{\mathrm{WT}}$ isolates, with 56,58 and $51 \%$, respectively (Fig. 1B), whereas the strawberry population had the lowest SdhB WT frequency (17\%). The frequency of isolates with the $\mathrm{SdhB}^{\mathrm{H} 272 \mathrm{R}}$ mutation ranged from $26 \%$ in apple to $51.4 \%$ in strawberry,

TABLE 1. Origin, numbers, and characteristics of Botrytis isolates used in this study

\begin{tabular}{|c|c|c|c|c|c|c|c|}
\hline \multirow[b]{2}{*}{ Host } & \multirow[b]{2}{*}{ Isolates $(n)$} & \multirow[b]{2}{*}{ Locations $(n)$} & \multirow[b]{2}{*}{ Geographic origin } & \multicolumn{4}{|c|}{ Year of collection } \\
\hline & & & & Before 2005 & 2008-2011 & 2013 & 2014 \\
\hline Apple & 65 & 10 & Washington & 17 & 48 & $\ldots$ & $\ldots$ \\
\hline Pear & 39 & 7 & Washington (20) and Oregon (19) & 7 & 32 & $\ldots$ & $\ldots$ \\
\hline Strawberry & 362 & 16 & $\begin{array}{l}\text { Florida(332), North Carolina (11), South } \\
\text { Carolina (19) }\end{array}$ & 61 & 80 & 122 & 99 \\
\hline
\end{tabular}

TABLE 2. Primers used for sequencing the SdhB, SdhC, and SdhD subunits of Botrytis cinerea

\begin{tabular}{|c|c|c|c|c|}
\hline Gene & Primer name & Sequence $\left(5^{\prime}-3^{\prime}\right)$ & Expected size (bp) & Reference \\
\hline \multirow[t]{2}{*}{$S d h B$} & Bc.SdhB-Fl & AAGGTATCTGCGGCAGTTGT & 850 & This study \\
\hline & IpBecEnd2 & CTCATCAAGCCCCCTCATTGATATC & & Leroux et al. (2010) \\
\hline \multirow[t]{3}{*}{$S d h C$} & $\mathrm{SdhCl}$ & ATCACGTGCCAGATTTCCTT & 1,100 & \\
\hline & SdhC-F2 & AACCGATACCTTCCGCATCA & 851 & \\
\hline & SdhC-R2 & ССССТСССААССТТААССТА & & This study \\
\hline \multirow[t]{2}{*}{$S d h D$} & SdhDl-F & TGATGACCTTGCACGTGACT & 950 & \\
\hline & SdhD2-R & AGCAGCATGTGTTTGACAGC & $\ldots$ & Leroux et al. (2010) \\
\hline
\end{tabular}


whereas the $\mathrm{SdhB}^{\mathrm{H} 272 \mathrm{Y}}$ mutation was found at 19,13 , and $12 \%$ in strawberry, pear, and apple, respectively, and was lower than $10 \%$ in blueberry and cherry (Fig. 1B). Overall, the $\mathrm{SdhB}^{\mathrm{N} 230 \mathrm{I}}$ and $\mathrm{SdhB}^{\mathrm{P} 225 \mathrm{~F}}$ mutations were found at frequencies $\leq 10 \%$ in apple, blueberry, and

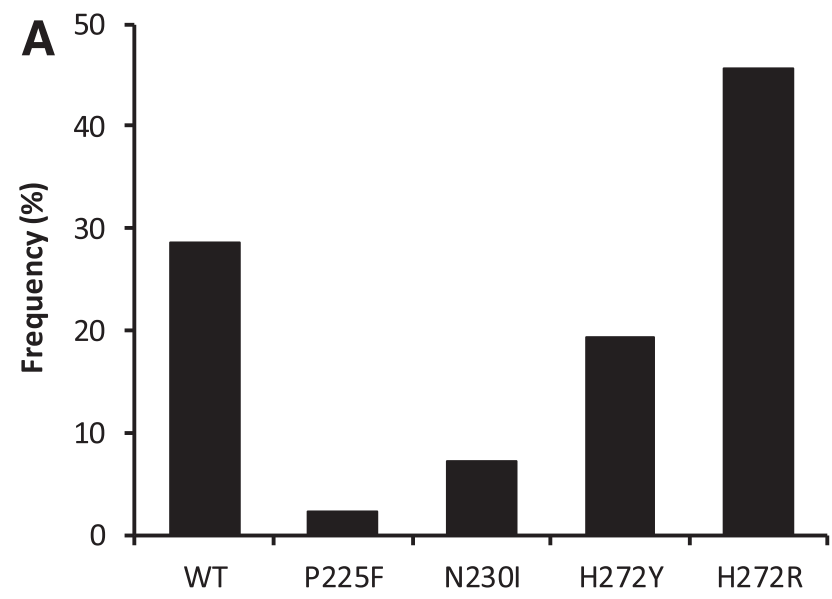

B

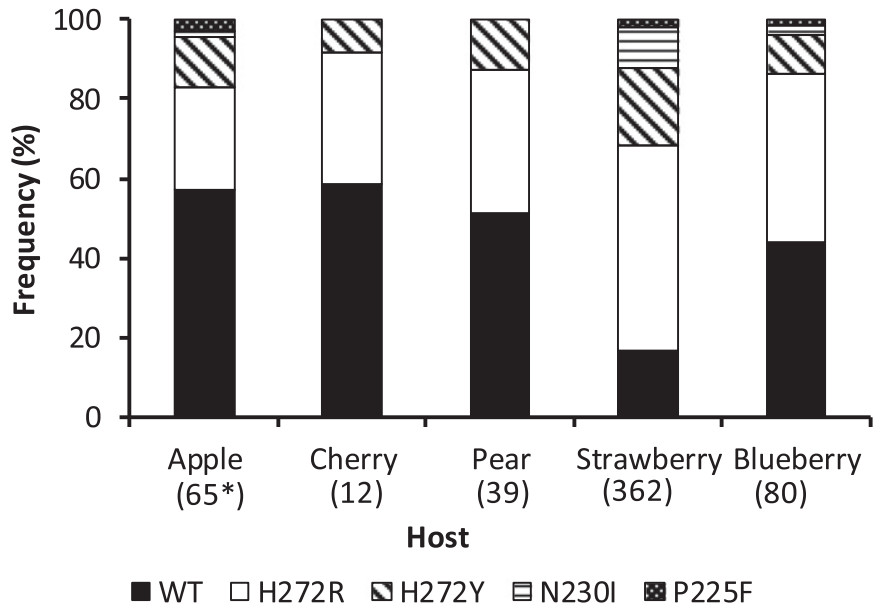

Fig. 1. A, Overall frequency of mutations in the SdhB subunit of 558 Botrytis cinerea isolates surveyed in this study and $\mathbf{B}$, their distribution by host. Numbers in parentheses indicate the number of isolates screened from each host and WT stands for wild type. Mutation characterization was conducted as described previously (Amiri et al. 2014). strawberry and were absent from the cherry and pear populations. No mutations were found in the SdhD subunit (data not shown).

Four simultaneous mutations are detected in the SdhC subunit of SDHI-exposed and nonexposed populations of B. cinerea. Sequencing the $\mathrm{SdhC}$ subunit of 40 field isolates revealed four simultaneous mutations in $\mathrm{SdhC}$ of some isolates (Fig. 2). A glycine to alanine mutation (SdhCG85A) occurred at codon 85 in the proximal quinone binding $\left(U_{Q}\right)$ site, adjacent to the well-conserved serine (Ser84) known to directly interact with the SDHIs. Another mutation from isoleucine to valine ( $\mathrm{SdhC}^{\mathrm{I} 93 \mathrm{~V}}$ ) occurred at codon 93 positioned near a proximal heme binding site $\left(H_{b}\right)$, whereas the third mutation from methionine to valine $\left(\mathrm{SdhC}^{\mathrm{M} 158 \mathrm{~V}}\right)$ occurred at codon 158 at the interface between the [3Fe-4S] cluster in $\mathrm{SdhB}$ and $U_{Q}$. The fourth mutation, valine to isoleucine ( $\mathrm{SdhCV168I)}$ at codon 168, was in a domain with unknown function in the $\mathrm{SdhD}$ interface binding site. Docking modeling studies showed that the four amino acids at which mutations occurred in $B$. cinerea are part of the $Q_{P}$ (Fig. 3). The positioning of SdhCG85 in the $U_{Q}$ site and the $\mathrm{C}^{\mathrm{M} 158}$ near the $[3 \mathrm{Fe}-4 \mathrm{~S}]$ cluster of $\mathrm{SdhB}$ are of a major importance for SDHIs docking and sensitivity.

The isolates without and with mutations in the SdhC were referred to as $\mathrm{C}^{-}$and $\mathrm{C}^{+}$genotypes, respectively, and a PCR-RFLP assay was developed to characterize them. A BsmaI digestion of the 850-bp $S d h C$ fragment amplified with the primer set SdhC-F2/ SdhC-R2 generated two fragments of 550 and $350 \mathrm{bp}$ in isolates with a glycine at codon $85\left(\mathrm{SdhC}^{\mathrm{G} 85}\right)$, whereas DNA from $\mathrm{C}^{+}$ isolates with an alanine at codon $85\left(\mathrm{SdhC}^{\mathrm{A} 5}\right)$ remained indigested (Fig. 4).

Among the 558 B. cinerea isolates screened using the PCR-RFLP assay, $415(74.4 \%)$ were from the $\mathrm{C}^{-}$genotype versus 143 isolates $(25.6 \%)$ from the $\mathrm{C}^{+}$genotype. The latter was present in all hosts but at higher frequencies in apple (40\%), pear $(31 \%)$, strawberry $(25 \%)$, and cherry $(25 \%)$ compared with $12.5 \%$ in blueberry (Fig. 5A).

The $\mathrm{C}^{+}$genotype was detected in both $\mathrm{SdhB}^{\mathrm{WT}}$ and $\mathrm{SdhB}$ field mutants; however, it was more frequent $(56 \%)$ in the SdhBWT isolates (Fig. 5B). Interestingly, a majority of $B$. cinerea isolates which were $\mathrm{S}$ to boscalid from tree fruit in addition to the isolates HS to boscalid from the Carolinas were from the $\mathrm{C}^{+}$genotype. Comparatively, the isolates with mutations in the $\mathrm{SdhB}$ contained lower frequencies of $\mathrm{C}^{+}$isolates, with the $\mathrm{SdhB}^{\mathrm{H} 272 \mathrm{R}}, \mathrm{SdhB}^{\mathrm{N} 230 \mathrm{I}}$, and $\mathrm{SdhB}^{\mathrm{H} 272 \mathrm{Y}}$ mutants showing $23.1,17.5$, and $14.1 \%$ of the $\mathrm{C}^{+}$ genotype, respectively, whereas all of the $11 \mathrm{SdhB}^{\mathrm{P} 225 \mathrm{~F}}$ mutants were from the $\mathrm{C}^{-}$genotype (Fig. 5B). The frequency of $\mathrm{C}^{+}$genotypes decreased slightly from $40 \%$ in isolates collected before 2004 (prior

\begin{tabular}{|c|c|c|}
\hline \multirow[t]{2}{*}{ Isolate } & \multirow[t]{2}{*}{ Phenotype } & SdhB \\
\hline & & 272 \\
\hline 05-30 & HS & STSCPSYWWNSEE LYRCHTILNCSRTCP \\
\hline 11-26 & HS & STSCPSYWWNSEE LYRCHTILNCSRTCP \\
\hline 05-31 & HS & STSCPSYWWNSEE LYRCHTILNCSRTCP \\
\hline $12-457$ & HS & STSCPSYWWNSEE LYRCHTILNCSRTCP \\
\hline 10-36 & MR & STSCPSYWWNSEE LYRCRTILNCSRTCP \\
\hline 11-67 & MR & STSCPSYWWNSEE LYRCRTILNCSRTCP \\
\hline 12-316 & $\mathrm{R}$ & STSCPSYWWNSEE LYRCYTILNCSRTCP \\
\hline 12-255 & $\mathrm{R}$ & STSCPSYWWI SEE LYRCHTILNCSRTCP \\
\hline $11-63$ & $\mathrm{~S}$ & STSCPSYWWNSEE LYRCHTILNCSRTCP \\
\hline $08-98$ & $\mathrm{~S}$ & STSCPSYWWNSEE LYRCHTILNCSRTCP \\
\hline $05-28$ & $\mathrm{~S}$ & STSCPSYWWNSEE LYRCHTILNCSRTCP \\
\hline $07-65$ & HR & STSCPSYWWNSEE LYRCRTILNCSRTCP \\
\hline $08-100$ & HR & STSCPSYWWNSEE LYRCRTILNCSRTCP \\
\hline $11-04$ & HR & STSCPSYWWNSEE LYRCRTILNCSRTCP \\
\hline $10-31$ & HR & STSCPSYWWNSEE LYRCYTILNCSRTCP \\
\hline $10-34$ & HR & STSCPSYWWNSEE LYRCYTILNCSRTCP \\
\hline $12-450$ & HR & STSCPSYWWI SEE LYRCHTILNCSRTCP \\
\hline $12-374$ & HR & STSCFSYWWNSEE LYRCHTILNCSRTCP \\
\hline
\end{tabular}

\begin{tabular}{|c|c|c|}
\hline \multicolumn{2}{|c|}{ SdhC } & \\
\hline 93 & 168 & \\
\hline NRITGCVLSGG & 150 LRHLAWDVGKTFKNATVIKTGWT & \\
\hline 83 MSALNRITGCVLSGG & 150 LRHLAWDVGKTFKNATVIKTGWT & $\mathbf{C}^{+}$ \\
\hline 83 MSALNRITGCVLSGG & 150 LRHLAWDVGKTFKNATVIKTGWT & $\mathbf{C}^{+}$ \\
\hline 83 MSALNRITGCVLSGG & 150 LRHLAWDVGKTFKNATVIKTGWT & $\mathbf{C}^{+}$ \\
\hline 83 MSALNRITGCVLSGG & 150 LRHLAWDVGKTFKNATVIKTGWT & $\mathbf{C}^{+}$ \\
\hline 83 MSALNRITGCVLSGG & 150 LRHLAWDVGKTFKNATVIKTGWT & $\mathbf{C}^{+}$ \\
\hline 83 MSALNRITGCVLSGG & 150 LRHLAWDVGKTFKNATVIKTGWT & $\mathbf{C}^{+}$ \\
\hline 83 MSALNRITGCVLSGG & 150 LRHLAWDVGKTFKNATVIKTGWT & $\mathbf{C}^{+}$ \\
\hline 83 MSGLNRITGCILSGG & 150 LRHLAWDMGKTFKNATVVKTGWT & $\mathrm{C}^{-}$ \\
\hline 83 MSGLNRITGCILSGG & 150 LRHLAWDMGKTFKNATVVKTGWT & $\mathrm{C}^{-}$ \\
\hline 83 MSGLNRITGCILSGG & 150 LRHLAWDMGKTFKNATVVKTGWT & $\mathrm{C}^{-}$ \\
\hline 83 MSGLNRITGCILSGG & 150 LRHLAWDMGKTFKNATVVKTGWT & $\mathrm{C}^{-}$ \\
\hline 83 MSGLNRITGCILSGG & 150 LRHLAWDMGKTFKNATVVKTGWT & $\mathrm{C}^{-}$ \\
\hline 83 MSGLNRITGCILSGG & 150 LRHLAWDMGKTFKNATVVKTGWT & $\mathrm{C}^{-}$ \\
\hline 83 MSGLNRITGCILSGG & 150 LRHLAWDMGKTFKNATVVKTGWT & $\mathrm{C}^{-}$ \\
\hline 83 MSGLNRITGCILSGG & 150 LRHLAWDMGKTFKNATVVKTGWT & $\mathrm{C}^{-}$ \\
\hline 83 MSGLNRITGCILSGG & 150 LRHLAWDMGKTFKNATVVKTGWT & $\mathrm{C}^{-}$ \\
\hline 83 MSGLNRITGCILSGG & 150 LRHLAWDMGKTFKNATVVKTGWT & $\mathrm{C}^{-}$ \\
\hline
\end{tabular}

Fig. 2. Alignment of deduced amino acid sequences of the $\mathrm{SdhB}$ (left) and SdhC (right) sequences of Botrytis cinerea isolates showing different levels of sensitivity to boscalid. In all, 40 strains were sequenced but only 18 are shown here. Residues involved in resistance to succinate dehydrogenase inhibitors (SDHIs) in both subunits are shaded. Residues in regular and bold fonts represent nonmutated and mutated amino acids, respectively. Asterisks indicate amino acids involved in SDHI binding. HS, S, MR, R, and HR indicate that the isolate is highly sensitive, sensitive, moderately resistant, resistant, or highly resistant, respectively, to boscalid. 
to SDHI registration) to 37 and $36 \%$ in isolates collected in the 2005 to-2009 and 2010-to-2014 periods, respectively (data not shown).

Botrytis $\mathrm{C}^{-}$and $\mathrm{C}^{+}$field isolates exhibit different sensitivities to multiple fungicides. The mean $\mathrm{EC}_{50}$ value of the $\mathrm{SdhB}^{\text {WT }}-\mathrm{C}^{+}$isolates was significantly lower for boscalid $\left(\chi^{2}=\right.$ $6.28, P=0.0037)$, penthiopyrad $\left(\chi^{2}=4.52, P=0.023\right)$, and carboxin $\left(\chi^{2}=3.75, P=0.041\right)$ compared with the $\mathrm{SdhB}^{\text {WT-C}} \mathrm{C}^{-}$isolates (Table 3). Similarly, the $\mathrm{SdhB}^{\mathrm{H} 272 \mathrm{R} / \mathrm{Y}}$ and $\mathrm{SdhB}^{\mathrm{N} 230 \mathrm{I}}$ isolates from the $\mathrm{C}^{+}$genotype were significantly more sensitive to all SDHIs, except to fluopyram. In contrast, all $\mathrm{SdhB}$ mutants from the $\mathrm{C}^{+}$ genotype had higher mean $\mathrm{EC}_{50}$ values for fluopyram than the $\mathrm{C}^{-}$ isolates, including the $\mathrm{SdhB}^{\mathrm{WT}}$ isolates $\left(\chi^{2}=3.02, P=0.033\right)$ and $\mathrm{SdhB}^{\mathrm{H} 272 \mathrm{Y}}\left(\chi^{2}=4.39, P=0.0360\right)$. The mean $\mathrm{EC}_{50}$ value of the $\mathrm{SdhB}^{\text {N230I-C }} \mathrm{C}^{+}$mutants for fluopyram was higher but not significantly different from those of the $\mathrm{SdhB}^{\text {N230I }} \mathrm{C}^{-}$genotype (Table 3 ). Ultimately, the $\mathrm{C}^{+}$isolates had slightly higher but not significantly different $\mathrm{EC}_{50}$ values for fludioxonil and fenhexamid compared with the $\mathrm{C}^{-}$isolates, whereas the two genotypes had similar sensitivities to cyprodinil (data not shown).

Mutations in the SdhC subunit affect sporulation, sclerotia production, and sensitivity to osmotic stress and ROS. The results from fitness parameter studies provide evidence for fitness penalty in $\mathrm{C}^{+}$isolates (Table 4). Mycelial growth on PDA was not affected by the SdhC mutations because growth was not significantly different, except for the $\mathrm{SdhB}{ }^{\mathrm{WT}}$ isolates. However, the $\mathrm{C}^{+}$isolates were more sensitive to osmotic stress and ROS, especially the $\mathrm{SdhB}^{\mathrm{Y} 272}$ and $\mathrm{B}^{1230}$ mutants from the $\mathrm{C}^{+}$genotype (Table 4). Sporulation was the most severely affected fitness parameter in $\mathrm{C}^{+}$ isolates on MYA (Fig. 6A and B), whereas $\mathrm{C}^{+}$isolates failed to sporulate on detached fruit after 10 days at $22^{\circ} \mathrm{C}$ (Table 4 ; Fig. $6 \mathrm{C}$ and D). Sclerotia production on PDA after 40 days at $22^{\circ} \mathrm{C}$ was lower in $\mathrm{C}^{+}$isolates in all $\mathrm{SdhB}$ genotypes and differences were significant in the SdhB WT, SdhB ${ }^{\mathrm{H} 272 \mathrm{Y}}$, and $\mathrm{SdhB}^{\mathrm{N} 230 \mathrm{I}}$ mutants (Table 4).

SDHI fungicides differentially reduce gray mold incidence of $\mathbf{C}^{+}$isolates on detached apple fruit. Boscalid and penthiopyrad applied preventively at the recommended field rate fully controlled the $\mathrm{SdhB}^{\mathrm{WT}} \mathrm{C}^{+}$isolates but not the $\mathrm{SdhB}^{\mathrm{WT}} \mathrm{C}^{-}$ isolate after 6 days, whereas fluopyram did not completely inhibit the $\mathrm{SdhB}^{\text {WT }} \mathrm{C}^{+}$isolates (Table 5). Similarly, gray mold incidence and severity were higher in fruit treated with boscalid and penthiopyrad (in contrast to fluopyram) and inoculated with the $\mathrm{SdhB}^{\mathrm{H} 272 \mathrm{R} / \mathrm{Y}_{-} \mathrm{C}^{-}}$mutants compared with the $\mathrm{SdhB}^{\mathrm{H} 272 \mathrm{R} / \mathrm{Y}_{-} \mathrm{C}^{+}}$ mutants (Table 5). After 4 days of incubation at room temperature,

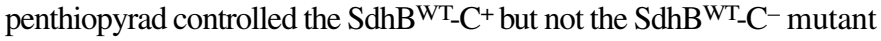
(Fig. 6F) and an opposite efficacy was seen for fluopyram on detached apple fruit (Fig. 6G).There was no difference in gray mold incidence and severity when the $\mathrm{SdhB}^{\mathrm{N}^{230 I}} \mathrm{C}^{-}$and $\mathrm{SdhB}^{\mathrm{N} 230 \mathrm{I}} \mathrm{C}^{+}$ were inoculated regardless of the SDHI used (data not shown).

\section{DISCUSSION}

Previous studies have linked SDHI resistance in $B$. cinerea to multiple mutations in the $\mathrm{SdhB}$ subunit (Amiri et al. 2014; Fernández-Ortuño et al. 2012; Leroux et al. 2010; Stammler et al. 2008, 2011; Veloukas et al. 2011, 2013; Weber and Hahn 2011). The potential higher risk for $B$. cinerea to develop resistance to the SDHIs is reinforced by the high polymorphism in the membraneanchored SdhC subunit reported in this study. Herein, we report for the first time on four simultaneous mutations in the SdhC subunit defining two coexisting Botrytis genotypes, $\mathrm{C}^{-}$and $\mathrm{C}^{+}$. The $\mathrm{C}^{+}$ genotype was found in all hosts investigated and was widespread in U.S. small-fruit fields and tree-fruit orchards. Our results indicate that the $\mathrm{C}^{+}$isolates do not correspond to B. pseudocinerea (Fournier et al. 2003) or Botrytis group S (Leroch et al. 2012), because all $\mathrm{C}^{+}$ isolates were characterized as $B$. cinerea. The mutations confer different sensitivity levels to the FRAC 7 fungicides; that is, a higher sensitivity to the pyridine (boscalid), pyrazole (penthiopyrad), and oxathiin (carboxin) carboxamides and reduced sensitivity to the benzamides (fluopyram). Moreover, these mutations clearly
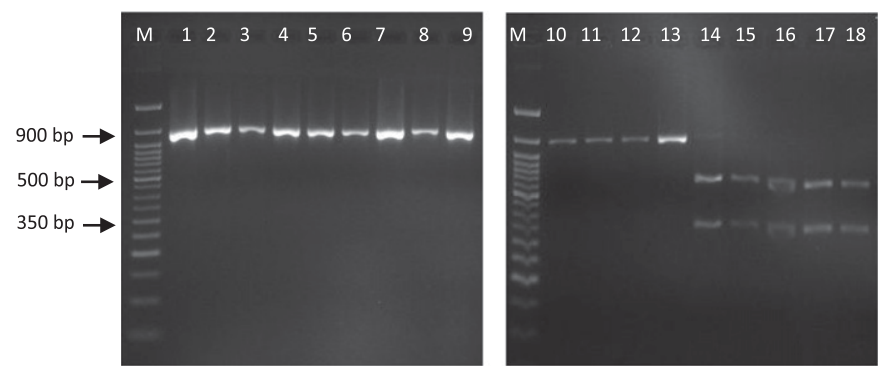

Fig. 4. Gel electrophoresis (2\% agarose) of nondigested (1 to 9) and BsmaIdigested (10 to 18) SdhC PCR fragments amplified using the primer set SdhC$\mathrm{F} 2 / \mathrm{SdhC}-\mathrm{R} 2$. Lanes 10 to 13 show isolates with mutations in SdhC $\left(\mathrm{C}^{+}\right)$, with the $\mathrm{SdhC} \mathrm{C}^{\mathrm{G} 85 \mathrm{~A}}$ mutation at codon 85 (also at codons 93, 158 and 168); lanes 14 to 18 show isolates without mutations $\left(\mathrm{C}^{-}\right)$at codon $85 . \mathrm{M}=$ molecular marker.

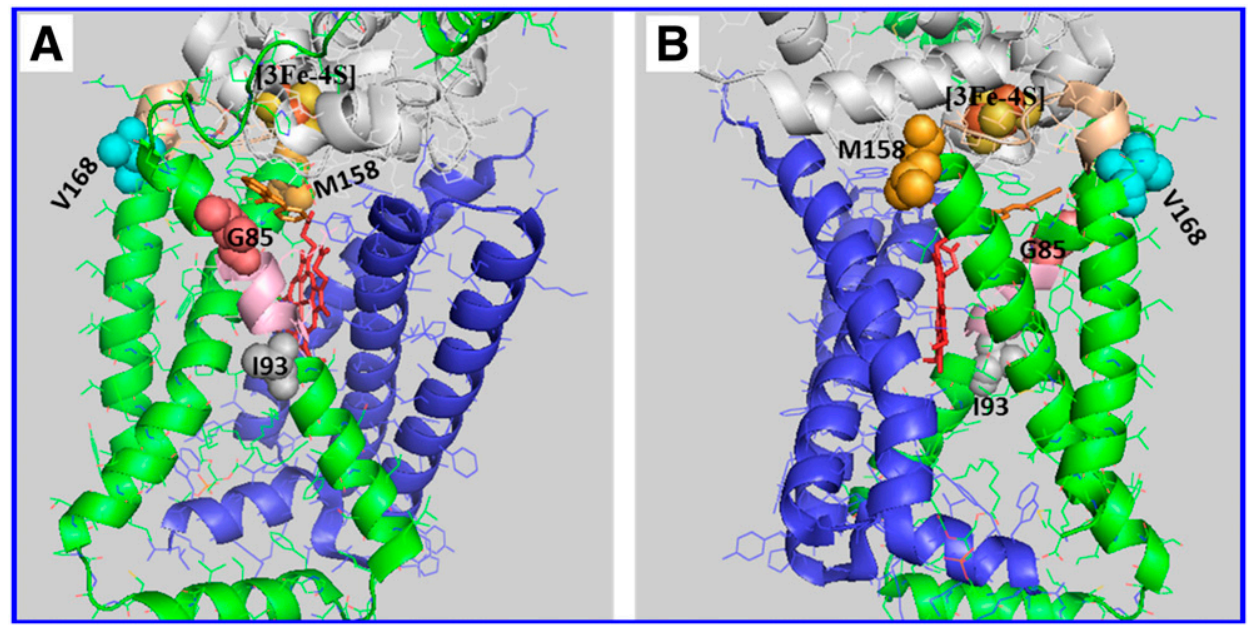

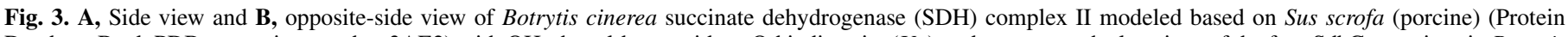

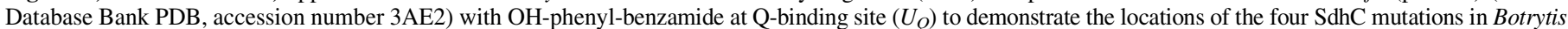

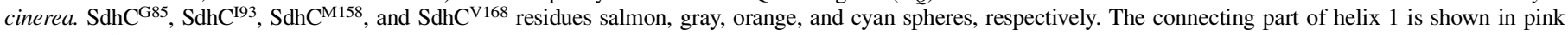

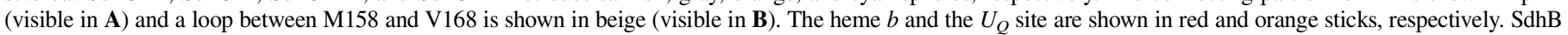
(partial), SdhC, and SdhD are shown in gray, green, and blue helices, respectively, the [3Fe-4S] cluster is shown in golden and reddish spheres within the SdhB. 
affected the fitness abilities of the $\mathrm{C}^{+} B$. cinerea isolates and likely their ability to outcompete and survive in field conditions. The positioning of the four mutations most likely caused an alteration in the $S D H$ structure which reduced or increased its affinity to the different SDHIs and, therefore, led to the different sensitivity levels observed herein and previously (Amiri et al. 2014; Fairchild et al. 2012; Fernández-Ortuño et al. 2012; Ishii et al. 2011; Leroux et al. 2010; Stammler et al. 2008).

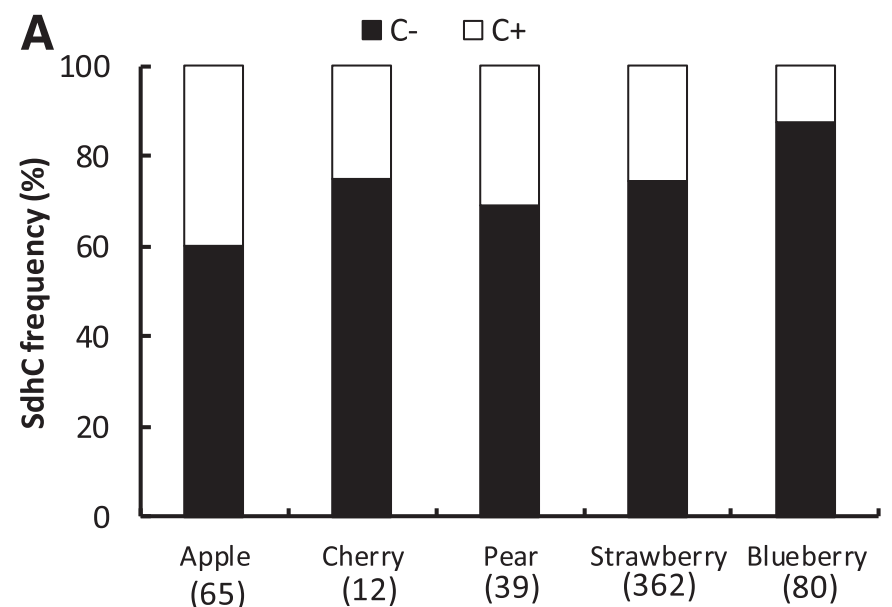

Host

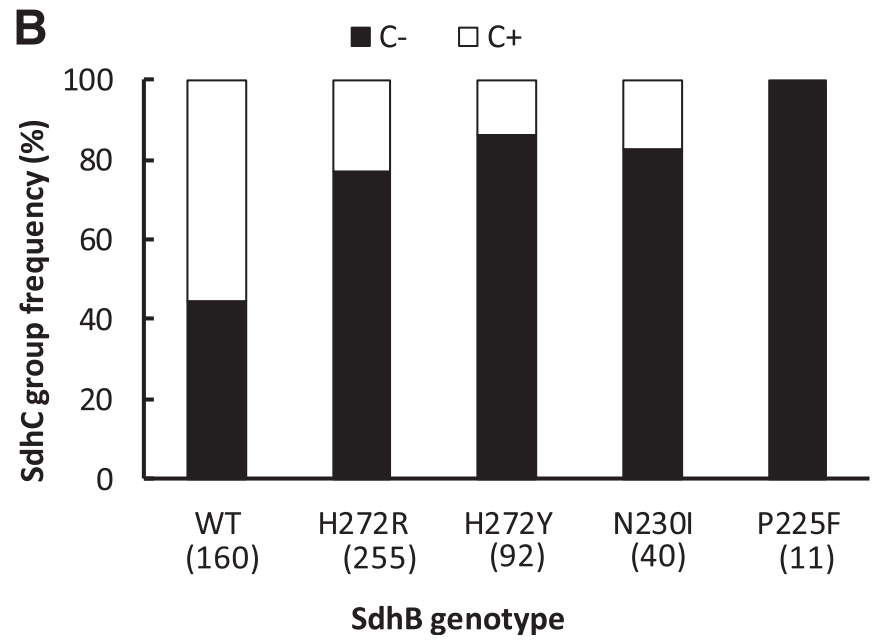

Fig. 5. Overall distribution of $\mathrm{C}^{-}$and $\mathrm{C}^{+}$genotypes among $\mathbf{A}$, hosts and $\mathbf{B}$, SdhB genotypes in 558 Botrytis cinerea isolates screened using the PCR restriction fragment length polymorphism assay. $\mathrm{C}^{-}$and $\mathrm{C}^{+}$refer to isolates without and with the four mutations in the SdhC subunit, respectively.
Homology modeling studies showed the four mutations in the $\mathrm{C}^{+}$ isolates, to be part of the quinone-binding pocket. Three residues at which mutations occurred ( $\mathrm{SdhC}^{\mathrm{G} 85}, \mathrm{SdhC}^{\mathrm{I} 93}$, and $\left.\mathrm{SdhC}^{\mathrm{M} 158}\right)$ are all part of domains known to be vital in interaction with ubiquinone inhibitors and the activity of the SDH complex. SdhCG85A has major importance because it is located in the $U_{Q}$ site, which includes $\mathrm{SdhCSer84}$, known to form a hydrogen bond with the O4-carbonyl oxygen of the quinone molecule and to interact directly with the SDHIs (Maklashina and Cecchini 2010; Ruprecht et al. 2009; Scalliet et al. 2012; Tran et al. 2006). SdhCI93V is at the downstream start of the $H_{b}$ site, which is primordial for the assembly and stability of the SDH complex (Haegerhaell et al. 1995; Nakamura et al. 1996). $\mathrm{SdhCM} 158 \mathrm{~V}$ is positioned in the iron-sulfur protein interface close to $U_{Q}$ and within the vicinity of the $[3 \mathrm{Fe}-4 \mathrm{~S}]$ cluster actively involved in electron transfer. Although homology modeling conducted in this and in a previous study (Glättli et al. 2009) has confirmed the positioning of residues important for SDHI sensitivity, it is important to characterize the actual SDH enzyme of Botrytis spp. because the low SdhC conservation between species would not allow definitive conclusions on the role of the different mutations found in the SdhC subunit.

The role of residues near the well-conserved $\mathrm{SdhCSer84}$ in sensitivity or resistance of the $\mathrm{C}^{+} B$. cinerea isolates to the SDHIs is supported by recent findings. In an effort to evaluate risks of fungicide resistance development in $M$. graminicola, mutants with amino acid substitutions at 10 different residues in SdhC have been selected by different SDHIs in laboratory conditions (Scalliet et al. 2012). Interestingly, an alanine substitution by a valine ( $\left.\mathrm{SdhC}^{\mathrm{A} 84 \mathrm{~V}}\right)$, equivalent to $\mathrm{SdhCG85 \textrm {A }}$ in $B$. cinerea, was the most selected by fluopyram (Scalliet et al. 2012). These mutants were highly resistant to fluopyram, whereas their sensitivity to boscalid was only slightly reduced. Moreover, in B. calthae, a specific pathogen of the wet woodland plant Calthae palustris (Hennebert and Groves 1963), isolates with significantly reduced sensitivity to fluopyram and boscalid had the SdhCG85A and $\mathrm{SdhC}^{193 V}$ mutations in the SdhC (Plesken et al. 2014), similar to the ones found in the B. cinerea $\mathrm{C}^{+}$ isolates. The authors also found two other mutations at codons 133 (I to F) and 138 ( $\mathrm{S}$ to $\mathrm{T}$ ) but did not indicate if the latter occurred simultaneously. Further evidence supporting our findings consists of a serine-to-proline substitution at codon 73 of SdhC which conferred moderate resistance and reduced sensitivity to boscalid and fluopyram in C. cassiicola (Ishii et al. 2011; Miyamoto et al. 2010). Interestingly, $\mathrm{SdhCS73}^{\mathrm{S}}$ of $C$. cassiicola aligned with $\mathrm{SdhC}^{\mathrm{A} 84}$ of $M$. graminicola and $\mathrm{SdhCG}^{\mathrm{G} 85}$ of $B$. cinerea (data not shown).

Although a direct effect on SDHI affinity with docking sites is the most likely mechanism, the positioning of $\mathrm{SdhC}^{\mathrm{M} 158}$ may have altered the electronic properties of the $[3 \mathrm{Fe}-4 \mathrm{~S}]$ cluster and the $U_{Q}$

TABLE 3. Sensitivity of Botrytis cinerea isolates with and without mutations in the SdhC subunit to four succinate dehydrogenase inhibitors

\begin{tabular}{|c|c|c|c|c|c|c|c|c|c|c|c|c|c|c|}
\hline \multicolumn{3}{|c|}{ Genotype $^{\mathrm{a}}$} & \multicolumn{3}{|c|}{ Boscalid } & \multicolumn{3}{|c|}{ Penthiopyrad } & \multicolumn{3}{|c|}{ Carboxin } & \multicolumn{3}{|c|}{ Fluopyram } \\
\hline SdhB & SdhC & $n$ & $\mathrm{EC}_{50}{ }^{\mathrm{b}}$ & $\chi^{2 \mathrm{c}}$ & $\mathrm{VF} / \mathrm{RF}^{\mathrm{d}}$ & $\mathrm{EC}_{50}$ & $\chi^{2}$ & $\mathrm{VF} / \mathrm{RF}$ & $\mathrm{EC}_{50}$ & $\chi^{2}$ & VF/RF & $\mathrm{EC}_{50}$ & $\chi^{2}$ & $\mathrm{VF} / \mathrm{RF}$ \\
\hline \multirow[t]{2}{*}{ WT } & $\mathrm{C}^{-}$ & 16 & 0.35 & $6.28 * *$ & 60 & 0.89 & $4.52 *$ & 78 & 1.89 & $3.75^{*}$ & 12 & 0.47 & $3.02 *$ & 78 \\
\hline & $\mathrm{C}^{+}$ & 20 & 0.17 & $\ldots$ & 78 & 0.11 & $\ldots$ & 55 & 0.75 & $\ldots$ & 3 & 0.76 & $\ldots$ & 154 \\
\hline \multirow[t]{2}{*}{$\mathrm{H} 272 \mathrm{R}$} & $\mathrm{C}^{-}$ & 23 & 4.51 & $15.46 * *$ & 451 & 0.61 & $11.21 * *$ & 61 & 5.00 & $15.41^{* *}$ & 23 & 0.46 & $3.58 *$ & 46 \\
\hline & $\mathrm{C}^{+}$ & 18 & 1.31 & $\ldots$ & 131 & 0.13 & $\ldots$ & 13 & 2.26 & $\ldots$ & 9 & 1.31 & $\ldots$ & 131 \\
\hline \multirow[t]{2}{*}{$\mathrm{H} 272 \mathrm{Y}$} & $\mathrm{C}^{-}$ & 21 & 3.99 & $4.76^{*}$ & 399 & 1.74 & $13.45^{* *}$ & 174 & 7.69 & $4.47 *$ & 18 & 0.11 & $4.39 *$ & 11 \\
\hline & $\mathrm{C}^{+}$ & 6 & 1.36 & $\ldots$ & 136 & 0.10 & $\ldots$ & 10 & 3.15 & $\ldots$ & 8 & 0.39 & $\ldots$ & 35 \\
\hline \multirow[t]{2}{*}{ N230I } & $\mathrm{C}^{-}$ & 10 & 4.75 & $11.79 * *$ & 475 & 1.05 & $4.57 *$ & 105 & 4.60 & $4.87 *$ & 12 & 1.74 & 0.32 & 174 \\
\hline & $\mathrm{C}^{+}$ & 6 & 0.94 & $\ldots$ & 94 & 0.79 & $\ldots$ & 79 & 2.35 & $\ldots$ & 9 & 1.86 & $\ldots$ & 186 \\
\hline
\end{tabular}

a Genotypes indicate isolates without mutations in $\mathrm{SdhB}$ (wild type $[\mathrm{WT}])$ or $\mathrm{SdhC}\left(\mathrm{C}^{-}\right)$or with mutations in $\mathrm{SdhB}(\mathrm{CH} 272 \mathrm{R} / \mathrm{Y}$ and $\mathrm{N} 230 \mathrm{I})$ and $\mathrm{SdhC}\left(\mathrm{C}^{+}\right)$.

b $\mathrm{EC}_{50}=$ mean effective concentrations in micrograms per milliliter of the fungicide to inhibit $50 \%$ germination and growth tube elongation.

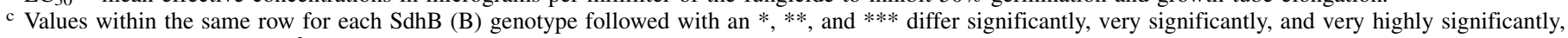
respectively, based on the $\chi^{2}$ test.

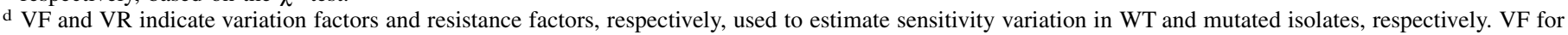
each genotype was calculated by dividing the highest $\mathrm{EC}_{50}$ value by the lowest $\mathrm{EC}_{50}$ value in the WT isolates, whereas $\mathrm{RF}$ for each genotype was calculated by dividing the highest $\mathrm{EC}_{50}$ value within each $\mathrm{SdhB}$ genotype by the lowest $\mathrm{EC}_{50}$ value in the WT isolates. 
TABLE 4. Evaluation of six fitness parameters in Botrytis cinerea isolates with and without mutations in the SdhC subunit

\begin{tabular}{|c|c|c|c|c|c|c|c|}
\hline \multicolumn{2}{|c|}{ Genotype $^{\mathrm{a}}$} & \multicolumn{3}{|c|}{ Growth $(\mathrm{mm})$ on $^{\mathrm{b}}$} & \multicolumn{2}{|c|}{ Sporulation $\left(\times 10^{5}\right)^{\mathrm{c}}$} & \multirow[b]{2}{*}{ Sclerotia $^{\mathrm{d}}$} \\
\hline SdhB & $\mathrm{SdhC}$ & PDA & $\mathrm{NaCl}(5 \%)$ & Paraquat $(20 \mathrm{mM})$ & MYA & Blackberry & \\
\hline \multirow[t]{2}{*}{ WT } & $\mathrm{C}^{-}$ & $39.8 \pm 4.1$ & $13.1 \pm 3.2$ & $21.3 \pm 3.1$ & $25.3 \pm 16.2$ & $129.6 \pm 84.5$ & $78.1 \pm 5.8$ \\
\hline & $\mathrm{C}^{+}$ & $22.7 \pm 5.2 *$ & $11.5 \pm 8.0$ & $17.2 \pm 5.3$ & $3.6 \pm 8.9^{*}$ & $0.0^{*}$ & $57.1 \pm 4.2 *$ \\
\hline \multirow[t]{2}{*}{ H272R } & $\mathrm{C}^{-}$ & $39.4 \pm 2.0$ & $10.5 \pm 2.5$ & $21.5 \pm 4.1$ & $44.2 \pm 44.3$ & $98.1 \pm 94.3$ & $47.2 \pm 6.2$ \\
\hline & $\mathrm{C}^{+}$ & $37.9 \pm 3.2$ & $07.5 \pm 1.1$ & $14.3 \pm 2.5^{*}$ & $29.8 \pm 35.9^{*}$ & $0.0^{*}$ & $58.5 \pm 5.6$ \\
\hline \multirow[t]{2}{*}{$\mathrm{H} 272 \mathrm{Y}$} & $\mathrm{C}^{-}$ & $39.4 \pm 2.1$ & $20.2 \pm 1.2$ & $11.8 \pm 2.9$ & $46.9 \pm 59.4$ & $78.4 \pm 51.0$ & $65.6 \pm 4.2$ \\
\hline & $\mathrm{C}^{+}$ & $38.9 \pm 2.4$ & $12.4 \pm 2.1 *$ & $6.1 \pm 1.2 *$ & $36.6 \pm 42.7 *$ & $0.0 *$ & $37.3 \pm 2.7 *$ \\
\hline \multirow[t]{2}{*}{$\mathrm{N} 230 \mathrm{I}$} & $\mathrm{C}^{-}$ & $41.0 \pm 1.1$ & $15.1 \pm 2.1$ & $10.9 \pm 3.1$ & $58.1 \pm 38.6$ & $132.1 \pm 42.8$ & $21.0 \pm 3.4$ \\
\hline & $\mathrm{C}^{+}$ & $39.5 \pm 1.0$ & $6.8 \pm 1.1 *$ & $3.2 \pm 1.9 *$ & $46.8 \pm 45.6^{*}$ & $0.0 *$ & $0.0 *$ \\
\hline
\end{tabular}

a Genotypes indicate isolates without mutations in $\mathrm{SdhB}$ (wild type [WT]) or SdhC $\left(\mathrm{C}^{-}\right)$or with mutations in $\mathrm{SdhB}(\mathrm{CH} 272 \mathrm{R} / \mathrm{Y}$ and $\mathrm{N} 230 \mathrm{I})$ and $\mathrm{SdhC}\left(\mathrm{C}^{+}\right)$.

${ }^{b}$ Mean growth after 5 days of incubation on potato dextrose (PDA), 10 days on $6 \% \mathrm{NaCl}$, and $20 \mathrm{mM}$ Paraquat at $22^{\circ} \mathrm{C}$. Data are means of 64 values from four isolates within each genotype, four replicate plates per isolate across two experimental runs.

c Number of spores $\times 10^{5}$ after 10 days at $22^{\circ} \mathrm{C}$ expressed as the mean from four isolates within each genotype, four replicate plates or fruit per isolate across two experimental runs. MYA = malt yeast agar.

${ }^{d}$ Sclerotia production on PDA. Number of sclerotia produced on PDA after 40 days incubation at $22^{\circ} \mathrm{C}$. Data are means of 64 values from four isolates within each genotype, four replicates. An asterisk indicates significant difference in values within the same column and each genotype, separately, based on $t$ test at $P \leq 0.05$.
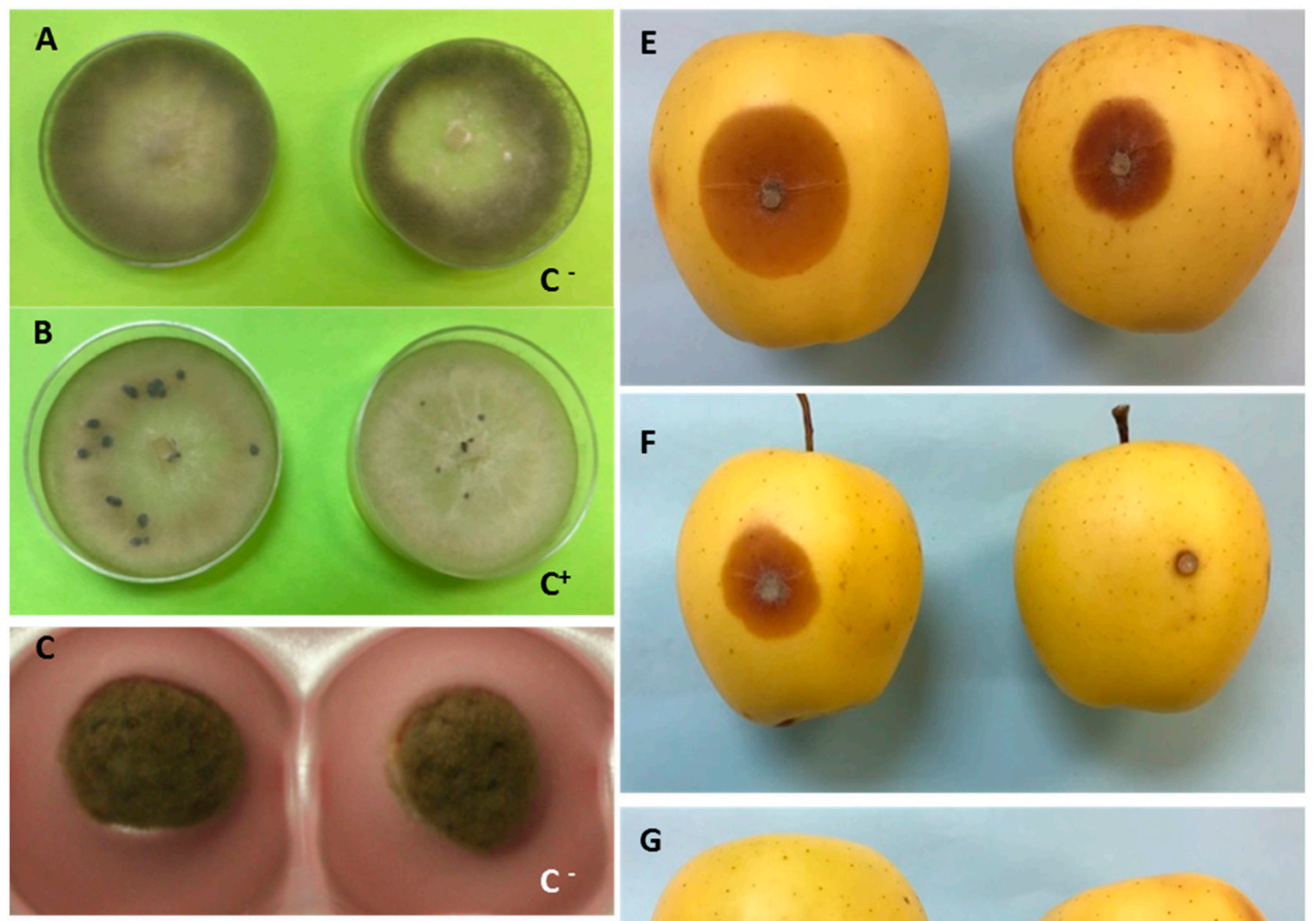

\section{G}
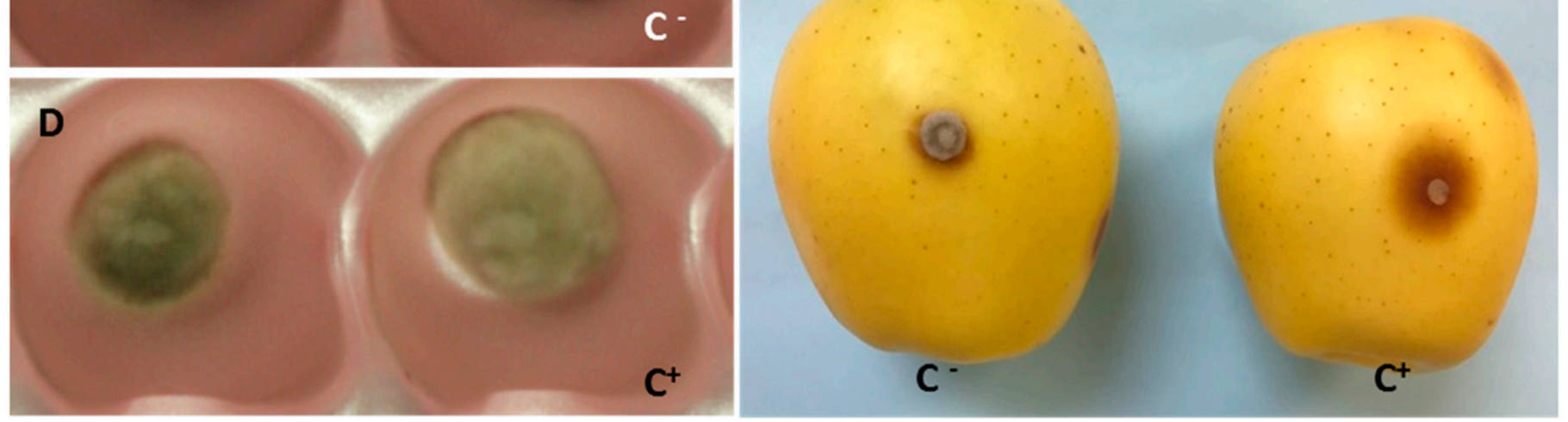

Fig. 6. Example of sporulation of Botrytis cinerea isolates from $\mathbf{C}^{-}$and $\mathrm{C}^{+}$genotypes on $\mathbf{A}$ and $\mathbf{B}$, malt yeast agar and $\mathbf{C}$ and $\mathbf{D}$, blackberry fruit after 10 days of incubation at $22^{\circ} \mathrm{C}$. Gray mold lesions on Golden Delicious apple $\mathbf{E}$, nontreated or treated with $\mathbf{F}$, penthiopyrad and $\mathbf{G}$, fluopyram and inoculated with $\mathrm{C}^{-}$(Bc8001) and $\mathrm{C}^{+}(\mathrm{Bc} 7425)$ isolates after 4 days of incubation at $22^{\circ} \mathrm{C}$. 


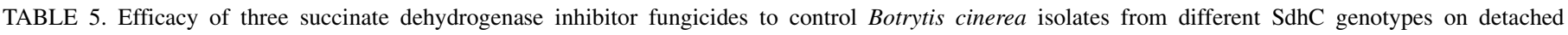
apple fruit ${ }^{\mathrm{a}}$

\begin{tabular}{|c|c|c|c|c|c|c|c|c|c|c|c|}
\hline \multirow[b]{2}{*}{ Isolate } & \multicolumn{2}{|c|}{ Genotype } & \multicolumn{3}{|c|}{ Boscalid } & \multicolumn{3}{|c|}{ Penthiopyrad } & \multicolumn{3}{|c|}{ Fluopyram } \\
\hline & SdhB & $\mathrm{SdhC}$ & $\mathrm{EC}_{50}$ & Incid & Les & $\mathrm{EC}_{50}$ & Incid & Les & $\mathrm{EC}_{50}$ & Incid & Les \\
\hline $\mathrm{Bc} 769$ & WT (H272-N230) & $\mathrm{C}^{-}$ & 0.4 & 12.8 & 12.0 & 1.14 & 8.0 & 12.0 & 1.57 & 0.0 & 0.0 \\
\hline Bc807 & WT (H272-N230) & $\mathrm{C}^{+}$ & 0.1 & 0.0 & 0.0 & 0.34 & 0.0 & 0.0 & 0.36 & 45.0 & 8.8 \\
\hline Bcl462 & WT (H272-N230) & $\mathrm{C}^{+}$ & 0.2 & 0.0 & 0.0 & 0.32 & 0.0 & 0.0 & 0.73 & 55.0 & 10.3 \\
\hline Bc8001 & $\mathrm{H} 272 \mathrm{R}$ & $\mathrm{C}^{-}$ & 4.0 & 100.0 & 22.6 & 2.02 & 12.5 & 8.6 & 0.38 & 0.0 & 0.0 \\
\hline Bc7425 & $\mathrm{H} 272 \mathrm{R}$ & $\mathrm{C}^{+}$ & 1.5 & 40.0 & 6.8 & 0.74 & 0.0 & 0.0 & 2.88 & 60.0 & 9.1 \\
\hline Bc4737 & $\mathrm{H} 272 \mathrm{Y}$ & $\mathrm{C}^{-}$ & 3.5 & 80.0 & 29.8 & 6.06 & 100.0 & 28.4 & 0.16 & 0.0 & 0.0 \\
\hline Bc9513 & $\mathrm{H} 272 \mathrm{Y}$ & $\mathrm{C}^{+}$ & 1.2 & 60.0 & 9.7 & 5.51 & 40.0 & 14.1 & 0.91 & 45.0 & 10.8 \\
\hline
\end{tabular}

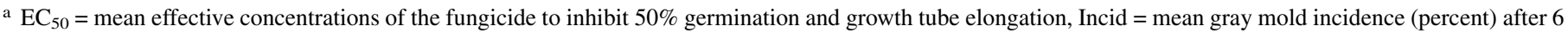
days of incubation at $22^{\circ} \mathrm{C}$ from eight replicate fruit across two experimental runs for each isolate within each genotype, and Les $=$ mean lesion in millimeters after 6 days of incubation at $22^{\circ} \mathrm{C}$ from eight replicate fruit across two experimental runs for each isolate within each genotype.

site or favored electron transfer to $H_{b}$, as reported recently with other mutations in E. coli (Anderson et al. 2014; Ruprecht et al. 2011). On the other hand, the $\mathrm{SdhC}^{193}$ residue is located next to $H_{b}$, which has been studied extensively and is thought to play a role in SDH assembly and stability (Hägerhäll 1997; Lancaster 2002; Lemarie and Grimm 2009). In fact, mutations in $H_{b}$ or its vicinity have not been found to affect SDH activity or SDHI sensitivity (Anderson et al. 2014; Oyedotun et al. 2004; Tran et al. 2006; Yankovskaya et al. 2003). However, mutations in SdhC and $H_{b}$ have been reported to cause ROS production and accumulation of succinate, known to cause hypoxia leading to ageing in different organisms (Friden et al. 1987; Ishii et al. 1998; Szeto et al. 2007). These studies corroborate our findings on mutation in $H_{b}$ causing increased ROS sensitivity as seen in $\mathrm{C}^{+}$isolates of $B$. cinerea. Finally, the SdhCV168I mutation occurred at a position with an unknown, apparent functional activity.

The presence of two Botrytis SdhC genotypes differentially sensitive to SDHIs and other fungicides in the field indicates different risks for resistance development and may shed some light on future gray mold management strategies. Because only boscalid has been used extensively in regions where the isolates have been collected, it is still unclear how the $\mathrm{C}^{-}$and $\mathrm{C}^{+}$populations have been selected. However, the predominance of the $\mathrm{C}^{+}$genotype in the SdhB ${ }^{\mathrm{WT}}$ isolates (i.e., those HS to boscalid from the Carolinas and those from tree fruit, which are less sprayed than strawberry) suggests a gradual negative selection pressure caused by boscalid on the $\mathrm{C}^{+}$genotype. In $M$. graminicola, boscalid selected preferentially

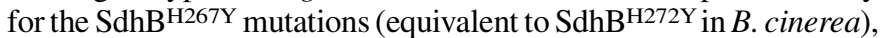
whereas fluopyram selected predominantly $(60 \%)$ for mutants carrying the $\mathrm{SdhCA84V/I}$ mutations (equivalent to $\mathrm{SdhCG85 \textrm {A }}$ in $B$. cinerea) (Scalliet et al. 2012). In contrast, fluopyram selected significantly less for isolates with mutations at the well-conserved residues $\mathrm{SdhC}^{\mathrm{S} 84}$ (3\%) and $\mathrm{C}^{\mathrm{R} 88}$ (18\%) (Scalliet et al. 2012). In addition to a higher potential for fluopyram to select more $\mathrm{SdhC}$ mutants, the reduced sensitivity of the $\mathrm{B}^{\mathrm{H} 272 \mathrm{Y}}$ isolates from the $\mathrm{C}^{+}$ group to the benzamides may put in jeopardy all SDHIs because of cross-resistance to all SDHIs in these mutants.

Although the effect of the four dependent mutations on SDHIs sensitivity was variable, we found evidence for a strong fitness penalty due to these mutations on the ability of the $\mathrm{C}^{+}$isolates to undergo severe selection pressure conditions compared with the $\mathrm{C}^{-}$ isolates. Overall, the $\mathrm{C}^{+}$isolates were less fit to sporulate and produce sclerotia, which limits their spread and survival under normal field conditions. Moreover, the $\mathrm{C}^{+}$isolates were more sensitive to water stress and ROS, which lowers their ability to survive under harsh conditions. This fitness cost combined with a negative selection pressure by most SDHIs, except fluopyram, may explain why the $\mathrm{C}^{+}$ genotypes are less frequent is the field. Our results on fitness costs due to the reported mutations corroborate previous findings on strong effects of mutations in SdhC and $H_{b}$ of Bacillus subtilis, Caenorhabditis elegans, and Saccharomyces cerevisiae (Friden et al.
1987; Ishii et al. 1998; Szeto et al. 2007) on their lifespan and fitness due to increased ROS production and accumulation of succinate, known to cause hypoxia and accelerated ageing.

We present evidence for increased risks for selecting populations resistant to the newly developed SDHIs in the gray mold fungus. The presence of multiple sites conferring reduced sensitivity to three major SDHIs from the pyrazole and pyridine groups in the $\mathrm{C}^{-}$ population, together with other mutations conferring reduced sensitivity to the benzamides in the $\mathrm{C}^{+}$population, can rapidly select for populations highly resistant to all SDHIs. This will significantly limit the role of SDHIs in future rotation programs aimed to manage gray mold. Future research should focus on studying the functional role of the four mutations, characterizing the genetic relatedness between the $\mathrm{C}^{-}$and $\mathrm{C}^{+}$populations, and evaluating the impact of spray regimes on selection and spread of such genotypes. Our findings emphasize that antiresistance strategies should be implemented at introduction of new fungicides rather than after resistance is observed, a time at which strategies aimed to slow selection may be too late to be effective.

\section{ACKNOWLEDGMENTS}

We thank G. Cecchini, VA Medical Center, San Francisco, for his assistance with SDH modeling; D. Fernández-Ortuño, Clemson University, for providing some of the isolates used in this study; and R. Martin, University of Florida-GCREC, for technical assistance.

\section{LITERATURE CITED}

Ali, M. E., and Amiri, A. 2018. Selection pressure pathways and mechanisms of resistance to the demethylation inhibitor-difenoconazole in Penicillium expansum. Front. Microbiol. 9:2472.

Amiri, A., Heath, S. M., and Peres, N. A. 2013. Phenotypic characterization of multifungicide resistance in Botrytis cinerea isolates from strawberry fields in Florida. Plant Dis. 97:393-401.

Amiri, A., Heath, S. M., and Peres, N. A. 2014. Resistance to fluopyram, fluxapyroxad, and penthiopyrad in Botrytis cinerea from strawberry. Plant Dis. 98:532-539.

Amiri, A., Zuniga, I. A., and Peres, N. A. 2018. Prevalence of Botrytis cryptic species in strawberry nursery transplants and strawberry and blueberry commercial fields in the Eastern United States. Plant Dis. 102:398-404.

Anderson, R. F., Shind, S., Hille, R., Rothery, R. A., Weiner, J. H., Rajagulguk, S., Maklashina, E., and Cecchini, G. 2014. Electron-transfer pathways in the heme and quinone-binding domain of complex II (succinate dehydrogenase). Biochemistry 53:1637-1646.

Avenot, H. F., Sellam, A., Karaoglanidis, G., and Michailides, T. 2008. Characterization of mutations in the iron-sulphur subunit of succinate dehydrogenase correlating with boscalid resistance in Alternaria alternata from California pistachio. Phytopathology 98:736-742.

Avenot, H. F., Sellam, A., and Michailides, T. 2009. Characterization of mutations in the membrane-anchored subunits AaSDHC and AaSDHD of succinate dehydrogenase from Alternaria alternata isolates conferring field resistance to the fungicide boscalid. Plant Pathol. 58:1134-1143.

Bardas, G. A., Veloukas, T., Koutiba, O., and Karaoglanidis, G. S. 2010. Multiple resistance of Botrytis cinerea from kiwifruit to SdhIs, QoIs and fungicides of other chemical groups. Pest Manage. Sci. 66:967-973. 
Cecchini, G. 2003. Function and structure of complex II or the respiratory chain. Annu. Rev. Biochem. 72:77-109.

De Miccolis Angelini, R. M., Habib, W., Rotolo, C., Pollastro, S., and Faretra, F. 2010. Selection, characterization and genetic analysis of laboratory mutants of Botryotinia fuckeliana (Botrytis cinerea) resistant to the fungicide boscalid. Eur. J. Plant Pathol. 128:185-199.

Elad, Y., Williamson, B., Tudzynski, P., and Delen, N. 2004. Botrytis spp. and diseases they cause in agric. Systems-An introduction. Pages 1-8 in: Botrytis: Biology, Pathology and Control. Y. Elad, B. Williamson, P. Tudzynski, and N. Delen, eds. Kluwer Academic Publishers, Dordrecht, The Netherlands.

Fairchild, K. L., Miles, L. A., Miles, T. D., and Wharton, P. S. 2012. Detection and characterization of boscalid resistance in Alternaria solani causing early blight on potatoes in Idaho. (Abstr.) Phytopathology 102:S4.36.

Fernández-Ortuño, D., Chen, F., and Schnabel, G. 2012. Resistance to pyraclostrobin and boscalid in Botrytis cinerea isolates from strawberry fields in the Carolinas. Plant Dis. 96:1198-1203.

Fernández-Ortuño, D., Grabke, A., Bryson, K. B., Amiri, A., Peres, N. A., and Schnabel, G. 2014. Fungicide resistance profiles in Botrytis cinerea from strawberry fields in seven southern U.S. States. Plant Dis. 98:825-833.

Fournier, N., Levis, C., Fortini, D., Leroux, P., Giraud, T., and Brygoo, Y. 2003. Characterization of $\mathrm{Bc}-h$ ch, the Botrytis cinerea homolog of the Neurospora crassa het-c vegetative incompatibility locus, and its use as a population marker. Mycologia 95:251-261.

Fraaije, B. A., Bayon, C., Atkins, S., Cools, H. J., Lucas, J. A., and Fraaije, M. W. 2012. Risk assessment studies on succinate dehydrogenase inhibitors, the new weapons in the battle to control Septoria leaf blotch in wheat. Mol. Plant Pathol. 13:263-275.

FRAC. 2018. FRAC code list. Fungicide Resistance Action Committee. https://www.frac.info/publications/downloads.

Friden, H., Rutberg, L., Magnuson, K., and Hederstedt, L. 1987. Genetic and biochemical-characterization of Bacillus subtilis mutants defective in expression and function of cytochrome b-558. Eur. J. Biochem. 168: 695-701.

Glättli, A., Stammler, G., and Schlehuber, S. 2009. Mutations in the target proteins of succinate dehydrogenase inhibitors (SDHI) and 14 $\alpha$-demethylase inhibitors (DMI) conferring changes in sensitivity-structural insights from molecular modeling. Pages 670-681 in: 9th Int. Conf. Plant Dis., Tours, France.

Haegerhaell, C., Fridén, H., Aasa, R., and Hederstedt, L. 1995. Transmembrane topology and axial ligands to hemes in the cytochrome b subunit of Bacillus subtilis succinate menaquinone reductase. Biochemistry 34:11080-11089.

Hägerhäll, C. 1997. Succinate: Quinone oxidoreductases: Variations on a conserved theme. Biochim. Biophys. Acta Bioenerg. 1320:107-141.

Hennebert, G. L., and Groves, J. W. 1963. Three new species of Botryotinia on Runuculaceae. Can. J. Bot. 41:341-370.

Horsefield, R., Iwata, S., and Byrne, B. 2004. Complex II from a structural perspective. Curr. Protein Pept. Sci. 5:107-118.

Horsefield, R., Yankovskaya, V., Sexton, G., Whitthingham, W., Shiomi, K., Ömura, S., Byrne, B., Cecchini, G., and Iwata, S. 2006. Structural and computational analysis of the quinone-binding site of complex II (succinateubiquinone reductase): A mechanism of electron transfer and proton conduction during ubiquinone reduction. J. Biol. Chem. 281:7309-7316.

Ishii, H., Miyamoto, T., Ushio, S., and Kakishima, M. 2011. Lack of crossresistance to a novel succinate dehydrogenase inhibitor, fluopyram, in highly boscalid-resistant isolates of Corynespora cassiicola and Podosphaera xanthii. Pest Manage. Sci. 67:474-482.

Ishii, N., Fujii, M., Hartman, P. S., Tsuda, M., Yasuda, K., Senoo-Matsuda, N., Yanase, S., Ayasawa, D., and Susuki, K. 1998. A mutation in succinate dehydrogenase cytochrome $\mathrm{b}$ causes oxidative stress and ageing in nematodes. Nature 394:694-697.

Ito, Y., Muaraguchi, H., Seshime, Y., Oita, S., and Yanagi, S. 2004. Flutolanil and carboxin resistance in Coprinus cinereus conferred by a mutation in the cytochrome b (560) subunit of succinate dehydrogenase complex (complex II). Mol. Genet. 272:328-335.

Kim, Y. K., and Xiao, C. L. 2010. Resistance to pyraclostrobin and boscalid in populations of Botrytis cinerea from stored apples in Washington State. Plant Dis. 94:604-612.

Lancaster, C. R. 2002. Succinate:quinone oxidoreductases: An overview. Biochim. Biophys. Acta 1553:1-6.

Lemarie, A., and Grimm, S. 2009. Mutations in the heme b-binding residue of the SdhC inhibit assembly or respiratory chain complex II in mammalian cells. Mitochondrion 9:254-260.

Leroch, M., Plesken, C., Weber, R. W. S., Kauff, F., Scalliet, G., and Hahn, M. 2012. Gray mold populations in German strawberry fields are resistant to multiple fungicides and dominated by a novel closely related to Botrytis cinerea. Appl. Environ. Microbiol. 79:159-167.

Leroux, P., Chapeland, F., Desbrosses, D., and Gredt, M. 1999. Patterns of cross-resistance to fungicides in Botryotinia fuckeliana (Botrytis cinerea) isolates from French vineyards. Crop Prot. 18:687-697.
Leroux, P., Gredt, M., Leroch, M., and Walker, A. S. 2010. Exploring mechanisms of resistance to respiratory inhibitors in field strains of Botrytis cinerea, the causal agent of gray mold. Appl. Environ. Microbiol. 76:6615-6630.

Maklashina, E., and Cecchini, G. 2010. The quinone-binding and catalytic site of complex II. Biochim. Biophys. Acta 1797:1877-1882.

Miyamoto, T., Ishii, H., Stammler, G., Koch, A., Ogawara, T., Tomita, Y., Fountaine, J. M., Ushio, S., Seko, T., and Kobori, S. 2010. Distribution and molecular characterization of Corynespora cassiicola isolates resistant to boscalid. Plant Pathol. 59:873-881.

Myresiotis, C. K., Karaoglanidis, G. S., and Tzavella-Klonari, K. 2007. Resistance of Botrytis cinerea isolates from vegetable crops to anilinopyrimidine, phenylpyrrole, hydroxyanilide, benzimidazole, and dicarboximide fungicides. Plant Dis. 91:407-413.

Nakamura, K., Yamaki, M., Sarada, M., Nakayama, S., Vibat, C. R. T., Gennis, R. B., Nakayashiki, T., Inokuchi, H., Kojima, S., and Kita, K. 1996. Two hydrophobic subunits are essential for the heme b ligation and functional assembly of complex II (succinate-ubiquinone oxidoreductase) from Escherichia coli. J. Biol. Chem. 271:521-527.

Oyedotun, K. S., Yau, P. F., and Lemire, B. D. 2004. Identification of the hem axial ligands in the cytochrome $b_{562}$ of the Saccharomyces cerevisiae succinate dehydrogenase. J. Biol. Chem. 279:9432-9439.

Plesken, C., Westrich, L. D., and Hahn, M. 2014. Genetic and phenotypic characterization of Botrytis calthae. Plant Pathol. 64:128-136.

Ruprecht, J., Iwata, S., Rothery, R. A., Weiner, J. H., Maklashina, E., and Cecchini, G. 2011. Perturbation of the quinone-binding site of complex II alters the electronic properties of the proximal $[3 \mathrm{Fe}-4 \mathrm{~S}]$ iron-sulfur cluster. J. Biol. Chem. 286:12756-12765.

Ruprecht, J., Yankovskaya, V., Maklashina, E., Iwata, S., and Cecchini, G. 2009. Structure of Escherichia coli succinate:quinone oxidoreductase with an occupied and empty quinone-binding site. J. Biol. Chem. 284: 29836-29846.

Scalliet, G., Bowler, J., Luksch, T., Kirchhofer-Allan, L., Steinhauer, D., Ward, K., Niklaus, M., Verras, A., Csukai, M., Daina, A., and Fonné-Pfister, R. 2012. Mutagenesis and functional studies with succinate dehydrogenase inhibitors in the wheat pathogen Mycosphaerella graminicola. PLoS One 7:e35429.

Shima, Y., Ito, Y., Kaneko, S., Hatabayashi, H., Watanabe, Y., Adachi, Y., and Yabe, K. 2009. Identification of three mutant loci conferring carboxinresistance and development of a novel transformation system in Aspergillus oryzae. Fungal Genet. Biol. 46:67-76.

Sierotzki, H., and Scalliet, G. 2013. A review of current knowledge of resistance aspects for the next-generation succinate dehydrogenase inhibitor fungicides. Phytopathology 103:880-887.

Stammler, G., Brix, H. D., Nave, B., Gold, R., and Schoefl, U. 2008. Studies on the biological performance of boscalid and its mode of action. Pages 45-51 in: Modern Fungicides and Antifungal Compounds. H. W. Dehne, H. B. Desing, U. Gisi, K. H. Kuck, P. E. Russel, and H. Lyr, eds. Deutsche Phytomedizinische Gesellschaf, Braunschweig, Germany.

Stammler, G., Glättli, A., Koch, A., and Schlehuber, S. 2011. Mutations in the target protein conferring resistance to SDHI fungicides. Pages 195-198 in: Modern Fungicides and Antifungal Compounds, Vol. VI. H. W. Dehne, H. B. Deising, U. Gisi, K. H. Kuck, P. E. Russell, and H. Lyr, eds. Deutsche Phytomedizinische Gesellschaf, Braunschweig, Germany.

Szeto, S. S. W., Reinke, S. N., Sykes, B. D., and Lemire, B. D. 2007. Ubiquinone-binding site mutations in the Saccharomyces cerevisiae succinate dehydrogenase generate superoxide and lead to accumulation of succinate. J. Biol. Chem. 282:27518-27526.

Tran, Q. M., Rothery, R. A., Maklashina, E., Cecchini, G., and Winer, J. H. 2006. The quinone binding site in Escherichia coli succinate dehydrogenase is required for electron transfer to the heme b. J. Biol. Chem. 281:32310-32317.

Veloukas, T., Leroch, M., Hahn, M., and Karaoglanidis, G. S. 2011. Detection and molecular characterization of boscalid-resistant Botrytis cinerea isolates from strawberry. Plant Dis. 95:1302-1307.

Veloukas, T., Leroch, M., Hahn, M., and Karaoglanidis, G. S. 2013. Differential effect of SdhB gene mutations on the sensitivity to SDHI fungicides in Botrytis cinerea. Plant Dis. 97:118-122.

Weber, R. W. S., and Hahn, M. 2011. A rapid and simple method for determining fungicide resistance in Botrytis. J. Plant Dis. Prot. 118:17-25.

Weiberg, A., Wang, M., Lin, F. M., Zhao, H. W., Zhang, Z. H., Kaloshian, I., Huag, H. D., and Jin, H. 2013. Fungal small RNAs suppress plant immunity by hijacking host RNA interference pathways. Science 342:118-123.

Williamson, B., Tudzynsk, B., Tudzynski, P., and van Kan, J. A. L. 2007. Botrytis cinerea: The cause of grey mould disease. Mol. Plant Pathol. 8:561-580.

Yankovskaya, V., Horsefield, R., Törnroth, S., Luna-Chavez, C., Miyoshi, H., Léger, C., Byrne, B., Cecchini, G., and Iwata, S. 2003. Architecture of succinate dehydrogenase and reactive oxygen species generation. Science 299:700-704.

Yin, Y. N., Kim, Y. K., and Xiao, C. L. 2011. Molecular characterization of boscalid resistance in field isolates of Botrytis cinerea from apple. Phytopathology 101:986-995. 